\title{
Boric Acid as an Accelerator of Cerium Surface Treatment on Aluminum
}

\author{
K. Cruz-Hernández, S. López-Leon, and F. J. Rodríguez-Gómez \\ Departamento de Ingeniería Metalúrgica, Edificio D Facultad de Química, Universidad Nacional Autónoma de México, \\ Edificio D, Ciudad Universitaria, 04510 México, DF, Mexico
}

Correspondence should be addressed to K. Cruz-Hernández; karycruzh@gmail.com

Received 12 October 2013; Accepted 4 December 2013; Published 16 January 2014

Academic Editor: Benjamin Valdez Salas

Copyright (c) $2014 \mathrm{~K}$. Cruz-Hernández et al. This is an open access article distributed under the Creative Commons Attribution License, which permits unrestricted use, distribution, and reproduction in any medium, provided the original work is properly cited.

\begin{abstract}
Aluminum pieces are often used in various industrial processes like automotive and aerospace manufacturing, as well as in ornamental applications, so it is necessary to develop processes to protect these materials, processes that can be industrialized to protect the aluminum as well or better than chromate treatments. The purpose of this research is to evaluate boric acid as an accelerator by optimizing its concentration in cerium conversion coatings (CeCC) with 10-minute immersion time with a concentration of $0.1 \mathrm{~g} \mathrm{~L}^{-1}$ over aluminum to protect it. The evaluation will be carried out by measuring anticorrosion properties with electrochemical techniques (polarization resistance, $R_{p}$, polarization curves, $\mathrm{PC}$, and electrochemical impedance spectroscopy, EIS) in $\mathrm{NaCl} 3.5 \%$ wt. aqueous solution and surface characterization with scanning electron microscopy (SEM).
\end{abstract}

\section{Introduction}

Among the most striking characteristics of aluminum is its versatility, and the range of physical and mechanical properties that can be developed is remarkable. The properties of aluminum that make this metal and its alloys the most economical and attractive options for a wide variety of uses are appearance, light weight, manufacturing versatility, physical properties, mechanical properties, and corrosion resistance [1]. Aluminum and its alloys are widely used in automotive and aerospace devices. Sometimes pieces of an aircraft are submitted to aggressive environments and changes of temperature as well as condensation, resulting in corrosion attack on them.

For many years, research for alternatives to chromatizing in order to diminish the damage to the environment has been carried out. Treatments that led to the development of other nontoxic coating processes with comparable adhesion properties and corrosion protection, such as conversion pretreatments formed by immersion in solutions containing phosphates, or cerium chloride, or other rare earth metal chlorides such as yttrium and lanthanum have been studied [2-5].
Approaches to cerium conversion coatings include different salts, variation on immersion temperature, anodizing, applying many layers, variation in concentration, surface activation, and use of accelerators like hydrogen peroxide [6-19].

The aim of this work is to improve understanding of accelerators on cerium conversion coatings, by studying the effect of different concentrations of boric acid as an accelerator added to CeCC at $0.1 \mathrm{~g} \mathrm{~L}^{-1}$ at $60^{\circ} \mathrm{C}$, and the role played by the substrate composition. The corrosion performance of treated aluminum surfaces that immersed 10 minutes in a cerium solution $\left(0.1 \mathrm{~g} \mathrm{~L}^{-1} \mathrm{CeCl}_{3} \cdot 7 \mathrm{H}_{2} \mathrm{O}\right.$ and dissolved in $0.1 \mathrm{M} \mathrm{NaCl}$ ) was analyzed. The electrochemical measurements were performed in a $3.5 \%$ wt $\mathrm{NaCl}$ aqueous solution and their response was correlated to the morphology and elemental composition.

\section{Experimental Process}

In this study, aluminum sheets used for testing had an area of $4.0 \mathrm{~cm}^{2}$ and a $1 \mathrm{~mm}$ thickness with a nominal composition shown in Table 1. Before immersion, metallic samples were cleaned and degreased using acetone. The cerium conversion 


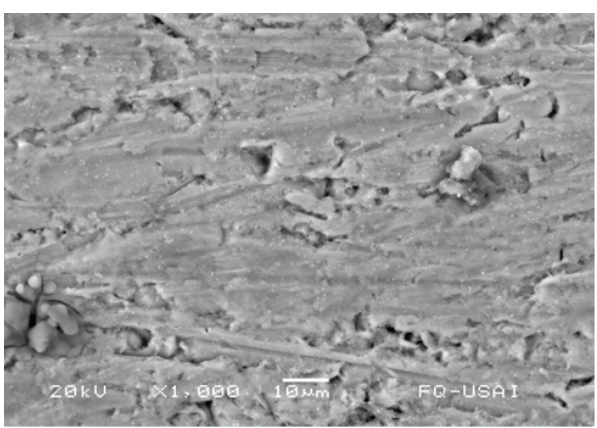

(a)

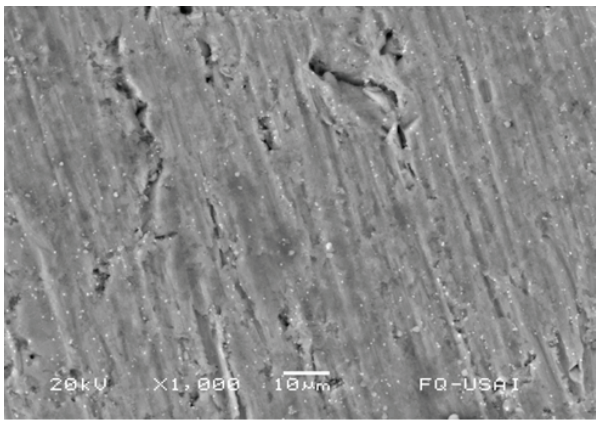

(c)

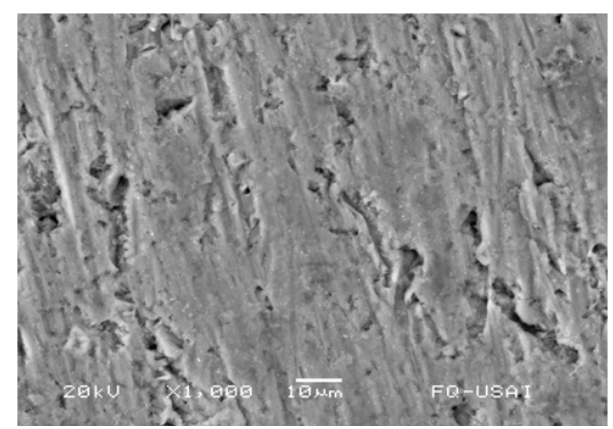

(b)

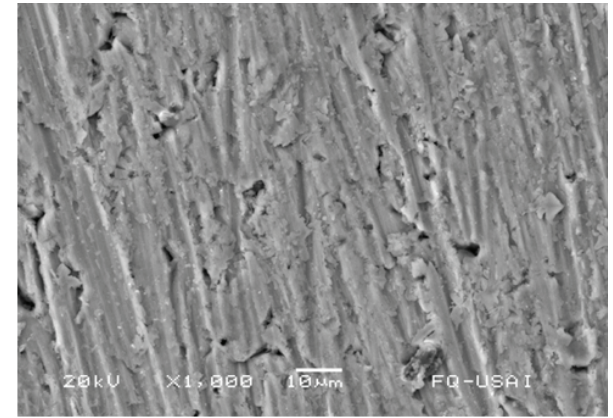

(d)

FIGURE 1: SEM images of aluminum conversion layers in cerium bath $\left(0.1 \mathrm{~g} \mathrm{~L}^{-1}\right)$ at different concentrations of accelerator (boric acid); (a) 0 , (b) 0.1, (c) 0.5 , and (d) $1 \mathrm{~g} \mathrm{~L}^{-1}$.

TABLE 1: Aluminum composition \% wt.

\begin{tabular}{lccccccc}
\hline $\mathrm{Mg}$ & $\mathrm{Mn}$ & $\mathrm{Fe}$ & $\mathrm{Si}$ & $\mathrm{Cr}$ & $\mathrm{Cu}$ & $\mathrm{Ti}$ & $\mathrm{Al}$ \\
\hline 0.0050 & 0.0109 & 0.0794 & 0.3201 & 0.0010 & 0.0633 & 0.0199 & Balance
\end{tabular}

coatings (CeCC) were obtained by dipping the samples into the cerium bath that was $0.1 \mathrm{M} \mathrm{NaCl}$ solution containing $0.1 \mathrm{~g} \mathrm{~L}^{-1} \mathrm{CeCl}_{3} \cdot 7 \mathrm{H}_{2} \mathrm{O}$ and boric acid as an accelerator $(0,0.1$, 0.5 , and $\left.1 \mathrm{~g} \mathrm{~L}^{-1}\right)$ at $60^{\circ} \mathrm{C}$ for 10 minutes. The coatings were then dried in warm air before any further handling or analysis.

Morphological aspects of the substrates and the conversion layers were studied by scanning electron microscopy (SEM/EDS) JEOL JSM-35C equipped with an EDS Voyager Tracor Northern Spectrometer. Chemical species distribution was also evaluated by EDS analysis.

Electrochemical characterization comprising polarization resistance $\left(R_{p}\right)$, polarization curves (PC), and AC impedance (EIS) was performed on the specimens treated with $\mathrm{CeCC}$ with and without accelerator. The samples were tested in a $\mathrm{NaCl} 3.5 \%$ wt aqueous solution at room temperature. A standard three-electrode setup and an electrochemical cell designed to work at room temperature were utilized. The cell consisted of an acrylic rectangular box $(60 \times 80 \times 100 \mathrm{~mm})$ with an exposed sample area of $0.785 \mathrm{~cm}^{2}$. The specimens were introduced by moderate pressure against an $\mathrm{O}$-ring, avoiding localized damage on the cerium-based layer.

The counter-electrode was a large-area graphite bar and the reference electrode was a saturated calomel electrode
SCE. The electrochemical measurements were obtained with an AC Gill potentiostat-galvanostat instrument connected to a personal computer.

Electrochemical impedance spectroscopy (EIS) was performed in the frequency range from $10^{4}$ to $10^{-1} \mathrm{~Hz}$, with ten measured points per frequency decade with amplitude of $10 \mathrm{mV}$ RMS open-circuit potential.

\section{Results and Discussion}

The SEM pictures of the cleaned and treated specimens are shown in Figure 1. It can be seen that the conversion coatings grew without a preferential direction, since they presented basically the same morphology as the bare substrates.

Figure 1 shows the micrographs for aluminum; before adding the accelerator to the CeCC the micrographs for aluminum showed some crystalline aggregates without a preferential direction (Figure 1(a)). Using boric acid as an accelerator at $0.1 \mathrm{~g} \mathrm{~L}^{-1}$, the nucleation of the CeCC increased the crystalline aggregates (Figure 1(b)); similarly, at $0.5 \mathrm{~g} \mathrm{~L}^{-1}$ of boric acid, the influence of the substrate, the microstructure, and the topography on the treatment's growth are observed as white points (Figure $1(\mathrm{c})$ ). Finally, the CeCC obtained at $1 \mathrm{~g} \mathrm{~L}^{-1}$, shown in Figure 1(d), appeared as smaller crystals than in $0.5 \mathrm{~g} \mathrm{~L}^{-1}$, similar to the sample with $0.1 \mathrm{~g} \mathrm{~L}^{-1}$. Moreover, observing Figures 1(a) to 1(d) it may be noticed that the coating growth was in the form of aggregates that doped 
TABLE 2: EDS Analysis for the elements and normalized results.

\begin{tabular}{lcc}
\hline & \multicolumn{2}{c}{$0.5 \mathrm{~g} / \mathrm{L} \mathrm{H}_{3} \mathrm{BO}_{3}$} \\
Element & Reaction area & $\begin{array}{c}\text { Matrix (uncovered area) } \\
\text { Atomic (\%) }\end{array}$ \\
\hline $\mathrm{O}$ & 30.74 & 18.56 \\
$\mathrm{Na}$ & 1.31 & 1.21 \\
$\mathrm{Al}$ & 66.81 & 79.12 \\
$\mathrm{Cl}$ & 0.77 & 1.10 \\
$\mathrm{Ce}$ & 0.37 & 100.00 \\
\hline Total & 100.00 & \\
\hline
\end{tabular}

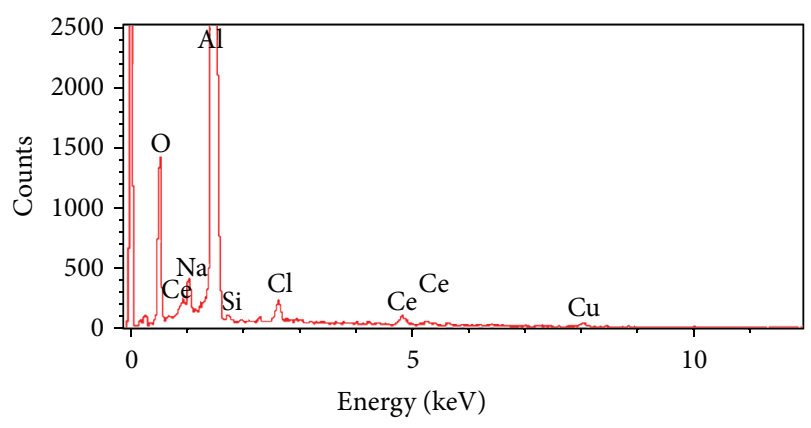

FIGURE 2: EDS spectra of analysis of the elements.

the native oxide of aluminum but did not constitute a continuous film as typically some oxidants do on a film surface.

Table 2 shows the EDS analysis of the aluminum samples obtained after the conversion treatment while Figure 2 shows spectra for analysis (where copper was discarded in the quantification because it was an impurity in the cerium chloride solution as determined by atomic absorption). These studies were performed in zones not covered by the CeCC and in an area where CeCC covered the substrate only for $0.5 \mathrm{gL}^{-1}$ of the accelerator sample. The table shows that the composition is quite different for each case, but the aluminum concentration is hugely diminished evidencing the formation of other species like Ce(III) oxide and a thicker aluminum oxide (alumina) layer. Similar behavior was obtained for the oxygen content that increased following the opposite trending, which could be related to alumina and $\mathrm{Ce}(\mathrm{III})$ oxide layer formation.

This work studied the effect of different concentrations of boric acid as an accelerator on CeCC baths and the role played by the substrate composition in this solution at $60^{\circ} \mathrm{C}$. The results obtained by SEM indicated that the formation and growth of $\mathrm{CeCC}$ on aluminum were not uniform over the surface; the heterogeneous distribution could be due to increase in the silicon concentration (Table 3 performed by statistical treatments of the 220 test of EDS analysis) that brings about formation of crystalline aggregates and promotes localized attack. Finally, it appears that the formation of CeCC could not produce a fully covered surface of specimens at higher accelerator concentration.

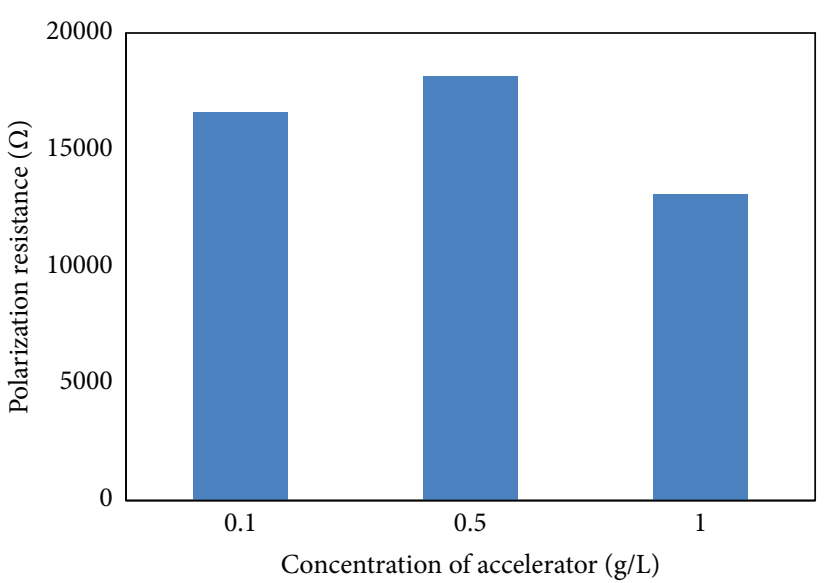

FIGURE 3: Polarization resistance values for $\mathrm{Al}$ samples treated with $\mathrm{CeCC}$ for different accelerator concentrations.

SEM analysis showed that a very thin film was formed on these substrates as a result of the cerium treatment and even obtained a better coat of cerium at the optimum concentration of accelerator.

Figure 3 summarizes the polarization resistance $\left(R_{p}\right)$ data obtained for substrates with and without accelerator at different concentrations on the cerium treatment. Comparing the behavior of the coatings produced at different concentrations of the accelerator, it will be seen that $0.5 \mathrm{~g} \mathrm{~L}^{-1}$ samples have shown the highest $R_{p}$ and showed a better protection against corrosion $\left(18167 \Omega \times \mathrm{cm}^{2}\right)$.

Anodic polarization curves for aluminum specimens in $\mathrm{NaCl} 3.5 \%$ wt are presented in Figure 4. The anodic curves show that the presence of an accelerator diminishes electrochemical activity, and at $0.5 \mathrm{~g} \mathrm{~L}^{-1}$ the curve shows lower current densities than for other concentrations. Although the electrochemical properties were different, it is demonstrated that the best behavior was obtained for $0.5 \mathrm{~g} \mathrm{~L}^{-1}$ of accelerator.

This behavior can be attributed to the formation of oxides of cerium, in which hydrogen peroxide acts as accelerator in oxide formation, because the standard reaction is produced by an increase of $\mathrm{pH}$ coming from the reduction of oxygen, favored by oxidation of metal. If hydrogen peroxide is added, the reaction occurs faster, due to the formation of hydroxyl ions coming from direct reduction of hydrogen peroxide, but if hydrogen peroxide decomposes into oxygen, oxygen reduction could occur $[13,20-22]$ :

$$
\begin{gathered}
\mathrm{O}_{2}+2 \mathrm{H}_{2} \mathrm{O}+4 \mathrm{e}^{-} \longrightarrow 4 \mathrm{OH}^{-} \\
\mathrm{H}_{2} \mathrm{O}_{2}+2 \mathrm{H}^{+}+2 \mathrm{e}^{-} \longrightarrow 2 \mathrm{H}_{2} \mathrm{O} \\
\mathrm{H}_{2} \mathrm{O}_{2}+2 \mathrm{e}^{-} \longrightarrow 2 \mathrm{OH}^{-}
\end{gathered}
$$

Also it has been proposed $[10,23]$ that the formation of oxides of $\mathrm{Ce}(\mathrm{III})$ and $\mathrm{Ce}(\mathrm{IV})$ occurs using boric acid as accelerator; this formation could be due to the reduction of boric acid resulting in local alkalinization. No thermal effect on boric acid decomposition has been reported, so its effect 
TABLE 3: Statistical treatments of 220 test of EDS analysis.

\begin{tabular}{|c|c|c|c|c|c|c|c|c|c|c|c|c|}
\hline \multirow{2}{*}{ Element } & \multicolumn{4}{|c|}{$\begin{array}{c}0.1 \mathrm{~g} / \mathrm{L} \mathrm{H}_{3} \mathrm{BO}_{3} \\
\text { Atomic } \%\end{array}$} & \multicolumn{4}{|c|}{$\begin{array}{c}0.5 \mathrm{~g} / \mathrm{L} \mathrm{H}_{3} \mathrm{BO}_{3} \\
\text { Atomic } \%\end{array}$} & \multicolumn{4}{|c|}{$\begin{array}{c}1 \mathrm{~g} / \mathrm{L} \mathrm{H}_{3} \mathrm{BO}_{3} \\
\text { Atomic } \%\end{array}$} \\
\hline & Minimum & Average & Maximum & $\begin{array}{l}\text { Standard } \\
\text { deviation }\end{array}$ & Minimum & Average & Maximum & $\begin{array}{l}\text { Standard } \\
\text { deviation }\end{array}$ & Minimum & Average & Maximum & $\begin{array}{l}\text { Standard } \\
\text { deviation }\end{array}$ \\
\hline $\mathrm{O}$ & 1.92 & 12.01 & 30.25 & 6.84 & 3.26 & 14.46 & 32.47 & 7.12 & 0.09 & 11.19 & 26.93 & 5.97 \\
\hline $\mathrm{Na}$ & 0.09 & 0.95 & 11.32 & 1.66 & 0.01 & 0.68 & 6.43 & 0.84 & 0.06 & 1.05 & 10.7 & 1.88 \\
\hline $\mathrm{Al}$ & 40.33 & 84.37 & 97.54 & 9.24 & 19.12 & 84.94 & 96.2 & 10.13 & 66.53 & 85.91 & 99.38 & 6.38 \\
\hline $\mathrm{Si}$ & 0.03 & 1.32 & 45.74 & 4.62 & 0.03 & 1.86 & 65.12 & 6.74 & 0.01 & 0.34 & 2.73 & 0.31 \\
\hline $\mathrm{Cl}$ & 0.03 & 1.14 & 11.43 & 1.92 & 0.03 & 0.83 & 7.58 & 1.00 & 0.05 & 1.33 & 13.09 & 2.28 \\
\hline $\mathrm{Fe}$ & 0.03 & 0.18 & 1.41 & 0.15 & 0.08 & 0.18 & 1.4 & 0.16 & 0.05 & 0.18 & 0.56 & 0.09 \\
\hline $\mathrm{Ce}$ & 0.07 & 0.24 & 0.28 & 0.05 & 0.1 & 0.4 & 0.47 & 0.08 & 0.07 & 0.05 & 0.09 & 0.03 \\
\hline
\end{tabular}

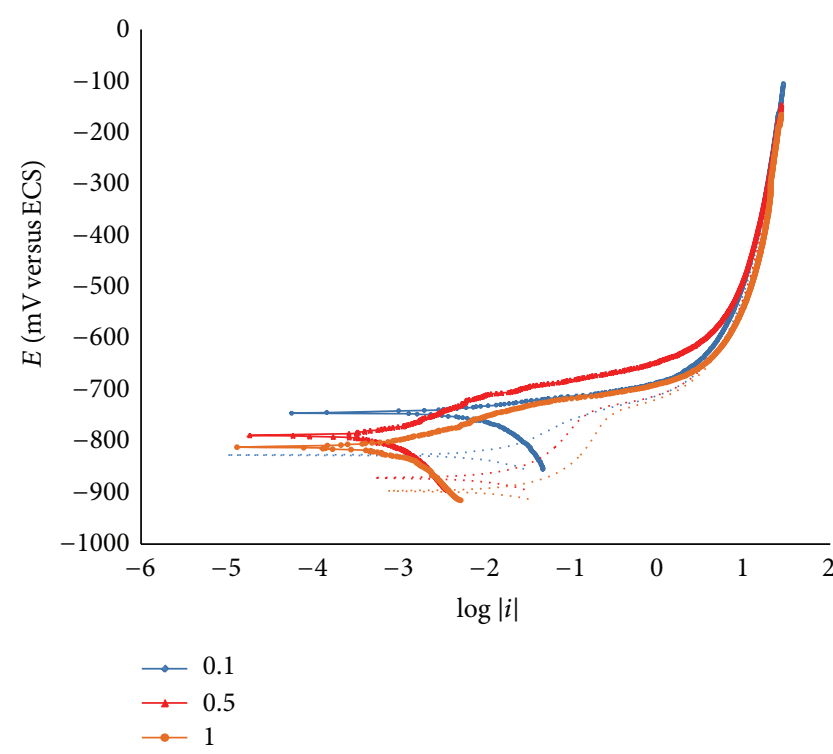

(a)

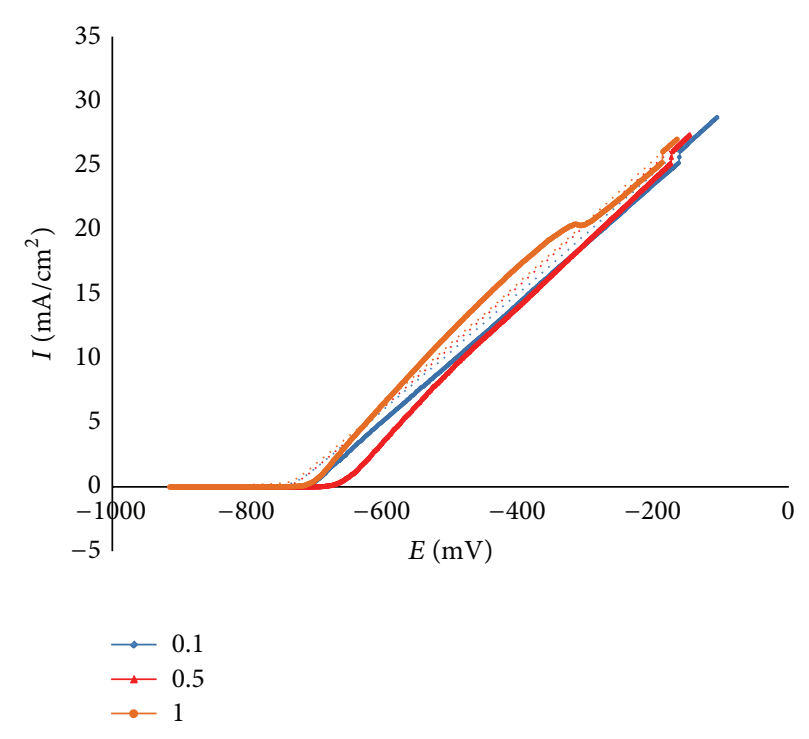

(b)

Figure 4: Polarization curves (a) and voltammograms (b) for aluminum conversion layers in cerium bath $\left(0.1 \mathrm{gL}^{-1}\right)$ at different concentrations of accelerator (boric acid); $0.1,0.5$, and $1 \mathrm{~g} \mathrm{~L}^{-1}$. Evaluated in $\mathrm{NaCl} 3.5 \%$ wt. aqueous solution.

could be continuous during immersion, even if the solution is heated.

Results for the electrochemical impedance spectroscopy obtained for aluminum specimens in $\mathrm{NaCl} 3.5 \%$ wt are shown in Figures 5(a)-5(c). All plots obtained showed depressed semicircles. Nyquist plots (Figure 5(a)) show semicircles with changes in diameter, attaining a maximum value for $0.5 \mathrm{~g} \mathrm{~L}^{-1}$ of accelerator sample, which is a trend also observed in the phase impedance modulus versus $\log f$ Bode diagrams (Figure 5(b)). The phase angle versus $\log f$ Bode diagrams for the specimens (Figure 5(c)) showed two time constants and higher phase angles for the samples containing $0.5 \mathrm{~g} \mathrm{~L}^{-1}$ of accelerator.

AC impedance results indicate that, due to the roughness of the substrate generated during the CeCC treatment, the surface can be modified by a localized attack, which may cause a decrease of the corrosion protection and changes in the solution's resistance. The higher impedances for the treated samples match the results obtained by $R_{p}, \mathrm{PC}$, and SEM observations and indicate a strong dependence of the chemical conversion treatments on the substrate. Some differences can be observed in the resistance solution and are attributed to the alumina layer formation and indicate a higher anticorrosive performance at $0.5 \mathrm{~g} \mathrm{~L}^{-1}$ of boric acid.

\section{Conclusions}

The results indicate that the conversion coatings grew without a preferential direction. The electrochemical test indicated that an optimum anticorrosive protection for the specimens evaluated might be achieved at $0.5 \mathrm{~g} \mathrm{~L}^{-1}$ of boric acid into the cerium bath. The uniformity and possibly the thickness of the CeCC seem to increase with the concentration of an accelerator, but, beyond $0.5 \mathrm{~g} \mathrm{~L}^{-1}$, it decreases again and this 


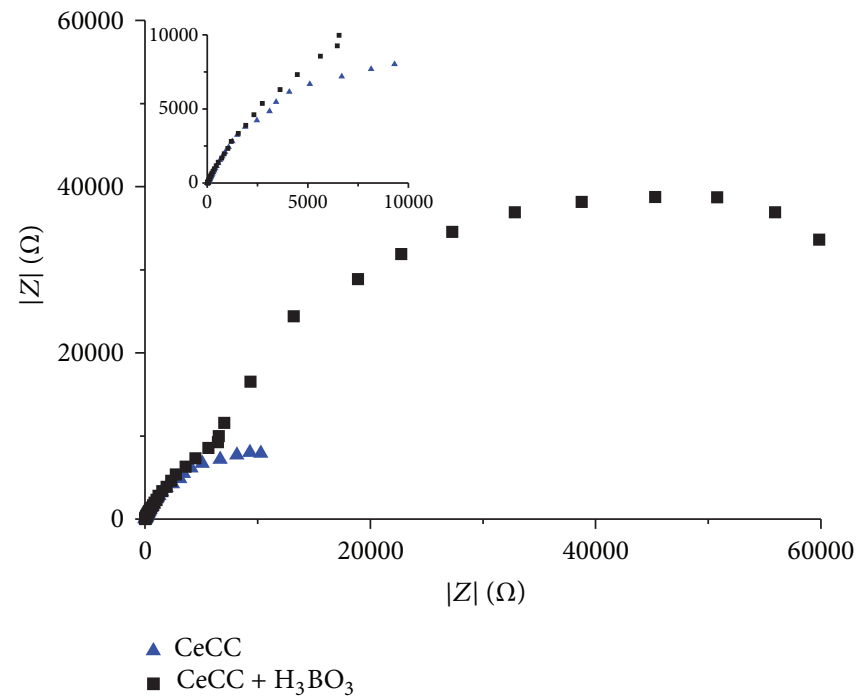

(a)

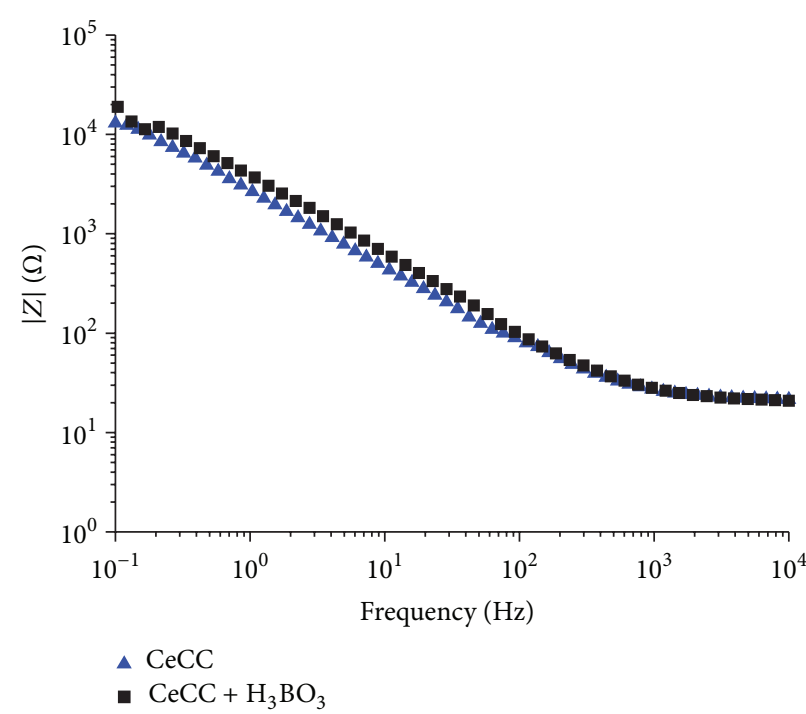

(b)

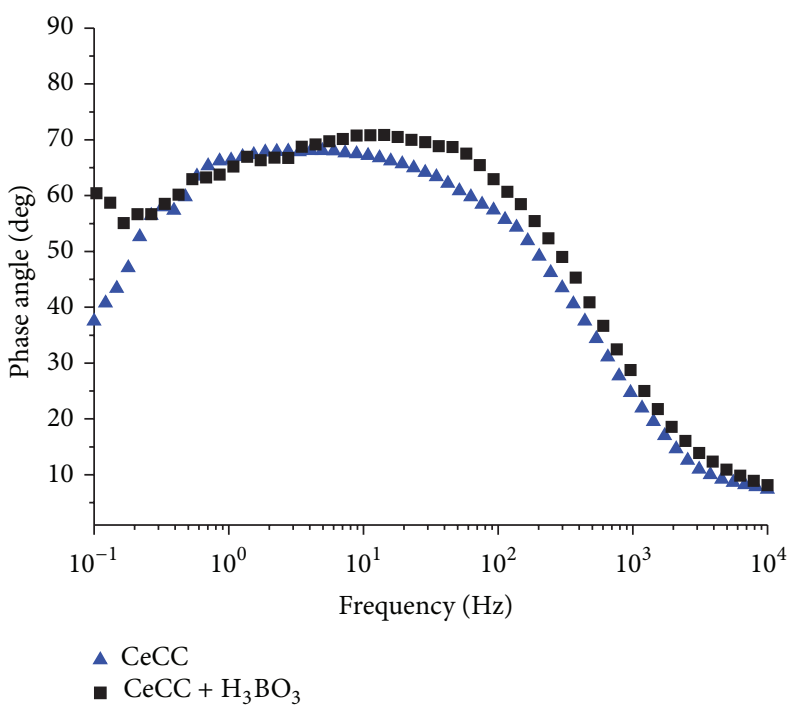

(c)

Figure 5: Nyquist and zoom of Nyquist (a) and Bode ((b)-(c)) impedance plots for treated and untreated aluminium samples in a 3.5\% wt $\mathrm{NaCl}$ aqueous solution.

could modify the surface by localized attack, thus reducing the anticorrosive protection.

\section{Conflict of Interests}

The authors declare that there is no conflict of interests regarding the publication of this paper.

\section{Acknowledgments}

The authors wish to thank the support from project PAPIIT IN105809. Karina Cruz also appreciates the financial support from Consejo Nacional de Ciencia y Tecnología (CONACYT) (PhD Scholarship) and Ivan Puente Lee for performing SEM and EDS analysis.

\section{References}

[1] E. L. Rooy, "Introduction to aluminum and aluminum alloys," in ASM Metals Handbook, vol. 2, ASM International, 1990.

[2] L. Fedrizzi, F. Deflorian, S. Rossi, L. Fambri, and P. L. Bonora, "Study of the corrosion behaviour of phosphatized and painted industrial water heaters," Progress in Organic Coatings, vol. 42, no. 1-2, pp. 65-74, 2001.

[3] G. Li, L. Niu, J. Lian, and Z. Jiang, "A black phosphate coating for C1008 steel," Surface and Coatings Technology, vol. 176, no. 2, pp. 215-221, 2004.

[4] L. Fedrizzi, F. Deflorian, and P. L. Bonora, "Corrosion behaviour of fluotitanate pretreated and painted aluminium sheets," Electrochimica Acta, vol. 42, no. 6, pp. 969-978, 1997. 
[5] B. R. W. Hinton and L. Wilson, "The corrosion inhibition of zinc with cerous chloride," Corrosion Science, vol. 29, no. 8, pp. 967985, 1989.

[6] M. Bethencourt, F. J. Botana, M. J. Cano, and M. Marcos, "High protective, environmental friendly and short-time developed conversion coatings for aluminium alloys," Applied Surface Science, vol. 189, no. 1-2, pp. 162-173, 2002.

[7] B. Y. Johnson, J. Edington, A. Williams, and M. J. O’Keefe, "Microstructural characteristics of cerium oxide conversion coatings obtained by various aqueous deposition methods," Materials Characterization, vol. 54, no. 1, pp. 41-48, 2005.

[8] M. Bethencourt, F. J. Botana, M. J. Cano, and M. Marcos, "Advanced generation of green conversion coatings for aluminium alloys," Applied Surface Science, vol. 238, no. 1-4, pp. 278-281, 2004.

[9] M. Dabalà, L. Armelao, A. Buchberger, and I. Calliari, "Ceriumbased conversion layers on aluminum alloys," Applied Surface Science, vol. 172, no. 3-4, pp. 312-322, 2001.

[10] Y. Xingwen, C. Chunan, Y. Zhiming, Z. Derui, and Y. Zhongda, "Study of double layer rare earth metal conversion coating on aluminum alloy LY12," Corrosion Science, vol. 43, no. 7, pp. 12831294, 2001.

[11] W. Zhang, J. Q. Li, Y. S. Wu, J. T. Xu, and K. Chen, "Corrosion resistance of conversion film formed on aluminium alloy using cerium salt surface treatment," Surface Engineering, vol. 18, no. 3, pp. 224-227, 2002.

[12] A. Decroly and J. Petitjean, "Study of the deposition of cerium oxide by conversion on to aluminium alloys," Surface and Coatings Technology, vol. 194, no. 1, pp. 1-9, 2005.

[13] M. A. Arenas and J. J. de Damborenea, "Growth mechanisms of cerium layers on galvanised steel," Electrochimica Acta, vol. 48, no. 24, pp. 3693-3698, 2003.

[14] M. A. Arenas, M. Bethencourt, F. J. Botana, J. de Damborenea, and M. Marcos, "Inhibition of 5083 aluminium alloy and galvanised steel by lanthanide salts," Corrosion Science, vol. 43, no. 1, pp. 157-170, 2001.

[15] W. G. Faherenheltz, O. 'Keefe MJ, H. Zhou, and J. T. Grant, "Characterization of cerium-based conversion coatings for corrosion protection of aluminum alloys," Surface and Coatings Technology, vol. 155, no. 2-3, pp. 208-213, 2002.

[16] B. Y. Johnson, J. Edington, and M. J. O’Keefe, “Effect of coating parameters on the microstructure of cerium oxide conversion coatings," Materials Science and Engineering A, vol. 361, no. 1-2, pp. 225-231, 2003.

[17] P. Campestrini, H. Terryn, A. Hovestad, and J. H. W. de Wit, "Formation of a cerium-based conversion coating on AA2024: relationship with the microstructure," Surface and Coatings Technology, vol. 176, no. 3, pp. 365-381, 2003.

[18] Y. Liu, M. A. Arenas, A. de Frutos et al., "Influence of nitric acid pre-treatment on Al-Cu alloys," Electrochimica Acta, vol. 53, no. 13, pp. 4454-4460, 2008.

[19] J. M. Sánchez-Amaya, M. Bethencourt, L. González-Rovira, and F. J. Botana, "Noise resistance and shot noise parameters on the study of IGC of aluminium alloys with different heat treatments," Electrochimica Acta, vol. 52, no. 23, pp. 6569-6583, 2007.

[20] A. H. Scott, Y. Pu, T. O’Keefe, and M. O’Keefe, “The phase stability of cerium species in aqueous systems I. E-pH diagram for the system," Journal of the Electrochemical Society, vol. 149, no. 12, pp. C623-C630, 2002.
[21] C. Motte, N. Maury, M. G. Olivier, J. P. Petitjean, and J. F. Willem, "Cerium treatments for temporary protection of electroplated steel," Surface and Coatings Technology, vol. 200, no. 7, pp. 2366-2375, 2005.

[22] L. Arurault, P. Monsang, J. Salley, and R. S. Bes, "Electrochemical preparation of adherent ceria coatings on ferritic stainless steel," Thin Solid Films, vol. 466, no. 1-2, pp. 75-80, 2004.

[23] X. Yu and G. Li, "XPS study of cerium conversion coating on the anodized 2024 aluminum alloy," Journal of Alloys and Compounds, vol. 364, no. 1-2, pp. 193-198, 2004. 

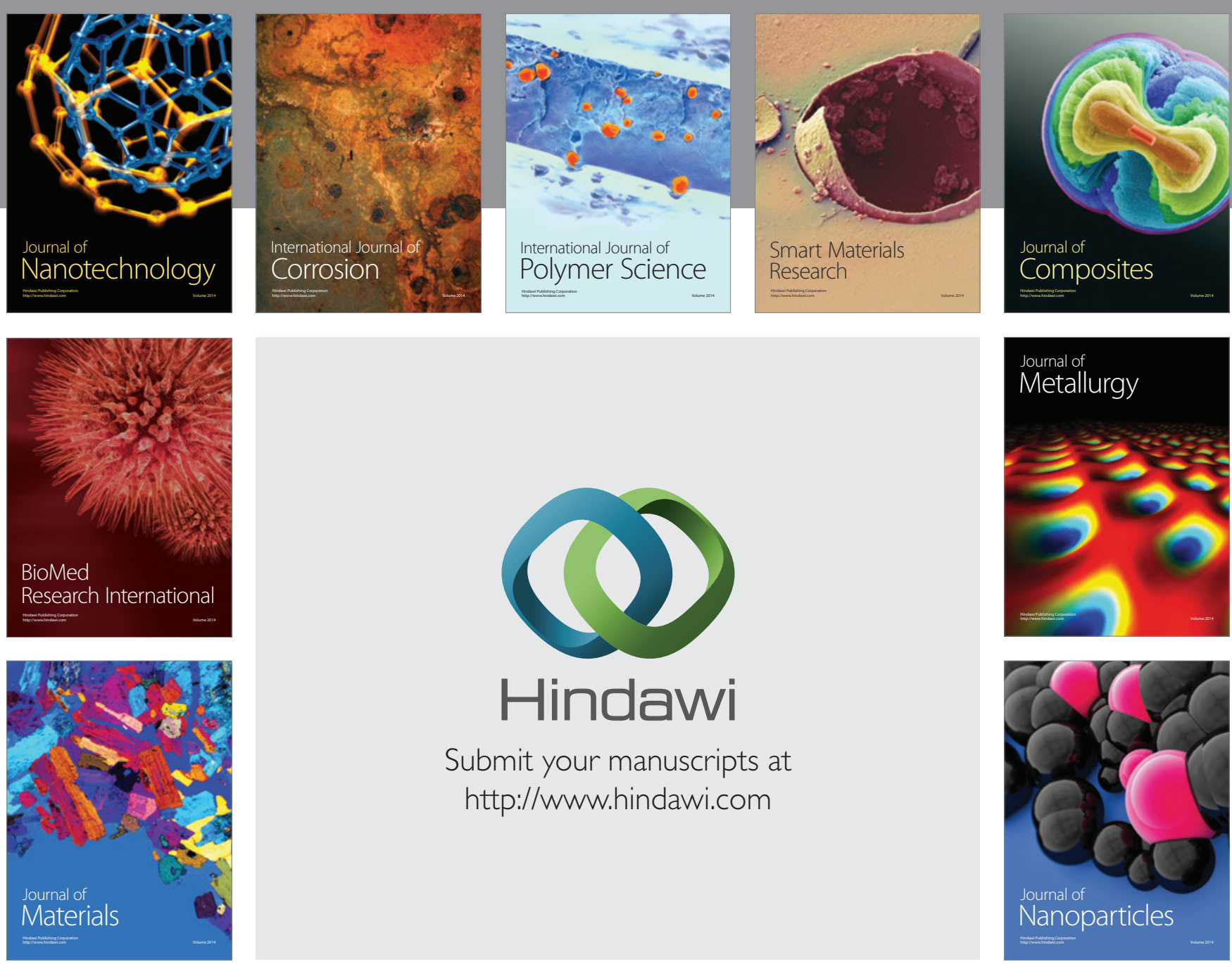

Submit your manuscripts at http://www.hindawi.com
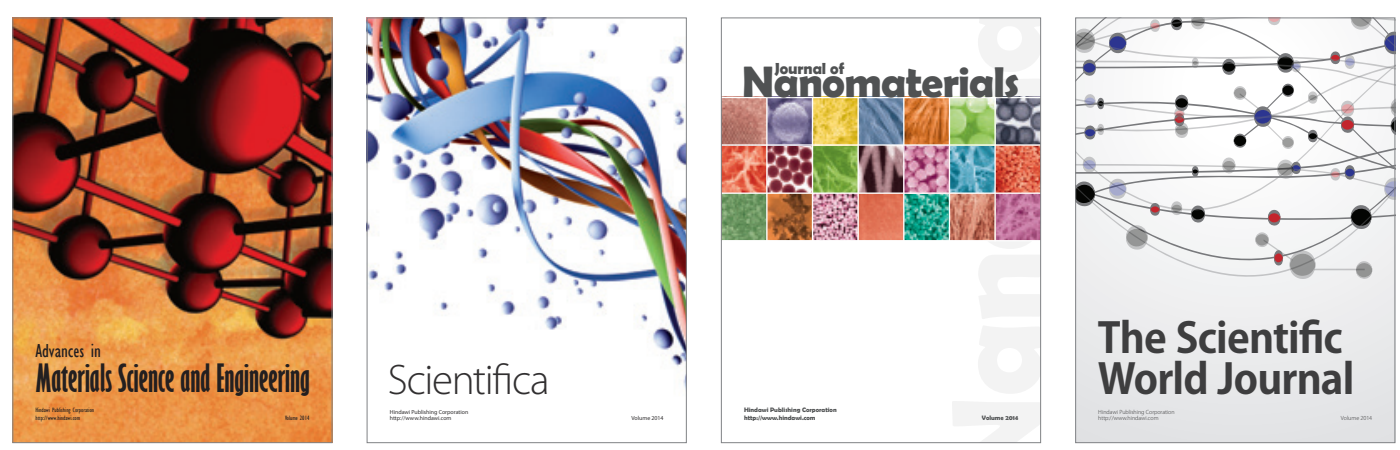

\section{The Scientific World Journal}
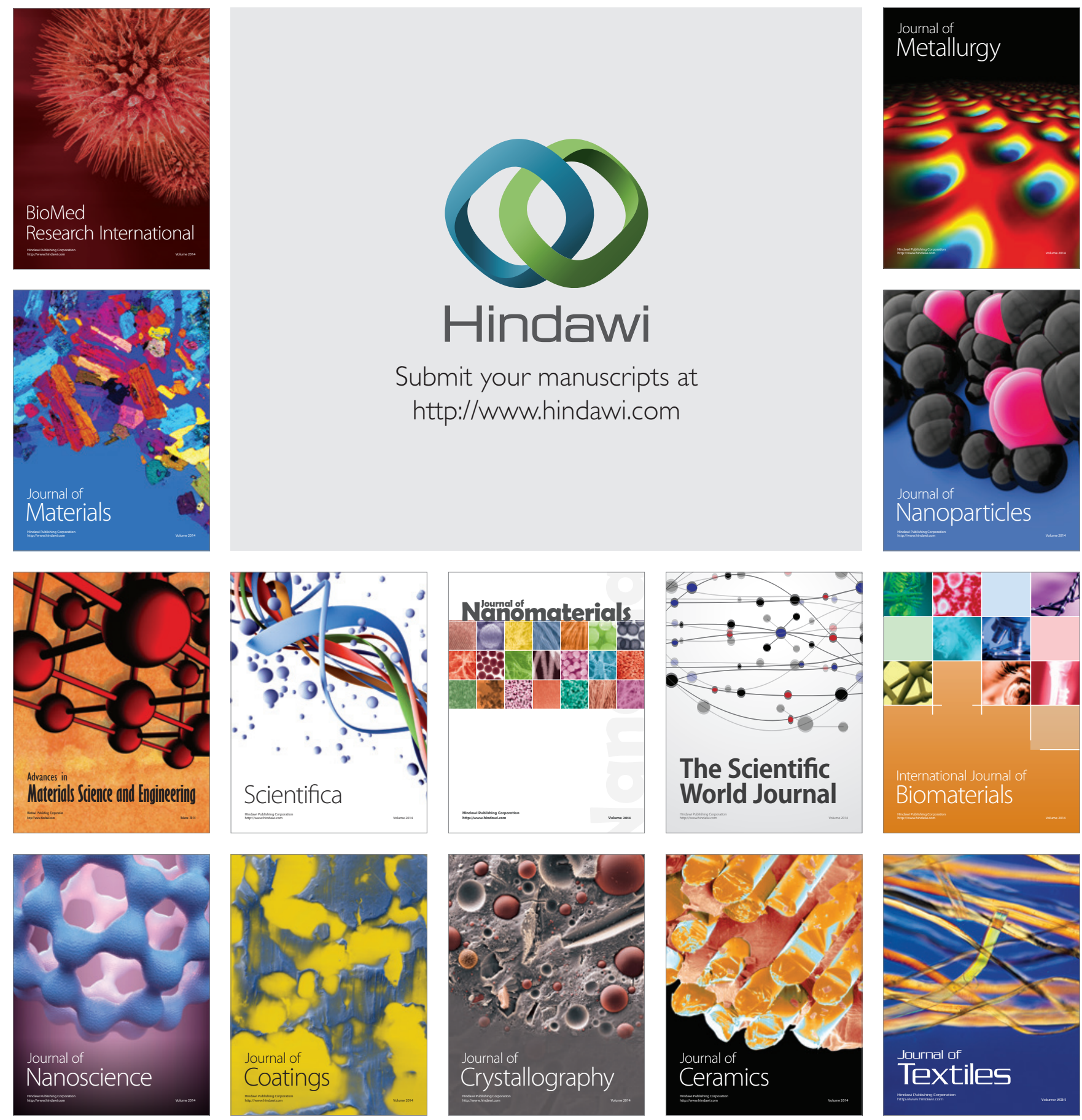